\title{
Relationship between external resistances, lung function changes and maximal exercise capacity
}

\author{
C.F. Melissant*+, J.-W.J. Lammers+, M. Demedts*
}

Relationship between external resistances, lung function changes and maximal exercise capacity. C.F. Melissant, J.-W.J. Lammers, M. Demedts. (OERS Journals Ltd 1998.

ABSTRACT: In upper airway obstruction (UAO) the relationship between the degree of obstruction, exercise limitation and lung function indices is not well established.

Therefore, we investigated in nine healthy subjects (age 36 \pm 9 yrs) the effects of two added resistances at the mouth $(\mathrm{R} 1=$ added resistance with $7.8 \mathrm{~mm}$ diameter; $\mathrm{R} 2=5.7$ $\mathrm{mm}$ ) on forced expiratory volume in one second (FEV1), peak expiratory flow (PEF), airway resistance $(R$ aw) and maximal breathing capacity (measured during $15 \mathrm{~s}=$ measured maximum breathing capacity $(\mathrm{MBCm})$; calculated as $\mathrm{FEV} 1 \times 37.5$ = calculated maximum breathing capacity $(\mathrm{MBC})$ ) on the one hand, and maximum exercise capacity $\left(W^{\prime} \max \right)$, minute ventilation $\left(V^{\prime} \mathrm{E}\right)$ and $\mathrm{CO}_{2}$ elimination $\left(V^{\prime} \mathrm{CO}_{2}\right)$ on the other.

We found that R1 had almost no influence on FEV1 but decreased PEF by $\sim 35 \%$ and increased $R$ aw by almost $300 \%$; it decreased $W^{\prime}$ max by merely $\sim 10 \%$ while maximal exercise ventilation ( $V^{\prime} \mathrm{Emax}$ ) was only $65 \%$ of control and only reached $\sim 40 \%$ $\mathrm{MBC}$ and $\sim 70 \% \mathrm{MBCm}$; yet $V^{\prime} \mathrm{E}$ and $V^{\prime} \mathrm{CO}_{2}$ were significantly reduced at high exercise levels indicating hypoventilation. With R2, FEV1 was reduced by $25 \%$ and PEF by $55 \%$, and $R$ aw was increased by $600 \%$; $W^{\prime} \max$ was $\sim 60 \%$ of control, $V^{\prime}$ Emax was only $35 \%$ of control and reached $\sim 30 \% \mathrm{MBC}$ and $\sim 60 \% \mathrm{MBCm}, V^{\prime} \mathrm{E}$ was already reduced at moderate exercise levels.

We conclude that : 1) an upper airway obstruction of $6 \mathrm{~mm}$ diameter (but not of 8 $\mathrm{mm}$ ) had a marked influence on maximum exercise capacity due to hypoventilation; 2) calculated maximum breathing capacity markedly overestimated measured maximum breathing capacity because the forced expiratory volume in one second is an insensitive index of upper airway obstruction and because it does not take inspiratory flow limitation into account; and 3) a $10 \%$ decrease in maximum exercise capacity was linearly related with a $7 \%$ decrease in the forced expiratory volume in one second and a $150 \%$ increase in airway resistance. $A$ 10\% decrease in maximal exercise ventilation was related to a $8.5 \%$ decrease in peak expiratory flow and $9 \%$ decrease in measured maximum breathing capacity.

Eur Respir J 1998; 11: 1369-1375.
*Dept of Pneumology, University Hospital Gasthuisberg (Leuven), Belgium. +Dept of Pneumology, University Hospital Utrecht, The Netherlands.

Correspondence: M. Demedts

Dept of Pneumology

University Hospital Gasthuisberg

Herestraat 49

B-3000 Leuven

Belgium

Fax: 3216346803

Keywords: Added resistance

lung function test

maximal breathing capacity

maximal exercise

upper airway obstruction

Received: January 51997

Accepted after revision February 271998

This study is supported by a grant of the NFWO Levenslijn project No. 7.0047.94
The relationship between the abnormalities in the different routine lung function tests and the degree of functional limitation during exercise is not well established in upper airway obstruction (UAO). On the contrary, in chronic obstructive pulmonary disease (COPD), for instance, a forced expiratory volume in one second (FEV1) of $60 \%$ predicted is generally associated with a peak expiratory flow (PEF) of 60-70\% pred and corresponds with a moderate physical impairment of $20-30 \%[1,2]$. Yet, in UAO, FEV1 will still be $70-80 \%$ pred when PEF is only $40-50 \%$ pred and it is not established what the clinical relevance is of each of these changes in terms of exercise limitation, although it is generally accepted that FEV1 is an insensitive test for UAO [3-5].

In several respiratory disorders the maximal breathing capacity (MBC) is considered a useful index of the degree of ventilatory impairment because the exercise limitation shows a good relationship with the reduction in MBC [6, 7]. In instances of ventilatory limitation the maximal exercise ventilation ( $V^{\prime}$ Emax) will often be more than $70 \%$
MBC, which is the normal ratio in healthy individuals. In addition, it has been claimed that $\mathrm{MBC}$ is a sensitive index of the ventilatory limitation in UAO [3, 8-13]. It seems, however, very probable that the calculated MBC (MBCc), derived from FEV1 (e.g. FEV1 ×37.5) will overestimate the actual ventilatory reserve in UAO, because of the already mentioned underestimation of the obstruction by FEV1. The relationship between FEV1 or MBCc and exercise capacity will, in addition, vary depending on the type of obstruction (i.e. fixed, variable extrathoracic or variable intrathoracic) because this will markedly influence the ratio of maximal expiratory over inspiratory flows [8]. Therefore, the measured $\mathrm{MBC}(\mathrm{MBCm})$ and not $\mathrm{MBC}$ appears to be the appropriate MBC index in UAO, because it also reflects inspiratory besides expiratory flow rates, in contrast to $\mathrm{MBC}_{\mathrm{c}}$ [14-17]. The relationship between $\mathrm{MBCm}$, $M B C c, V^{\prime}$ Emax and exercise capacity is, however, not well established in UAO. Yet LiNDSTEDT et al. [18] have shown that added resistances with an orifice diameter of less than $\sim 10 \mathrm{~mm}$ cause a decrease in maximal $\mathrm{O}_{2}$ uptake $\left(V^{\prime} \mathrm{O}_{2} \max \right)$ 
which is proportional to that in PEF and peak inspiratory flow (PIF). In addition, the relationship between the degree of exercise limitation and the anatomic obstruction in UAO is not well known. The reliability of radiology in estimating the diameter or cross-sectional area of UAO has been questioned because it is not well correlated with functional changes and because it is not able to visualize all UAOs [19].

The purpose of the present study was, therefore, to measure in UAO : 1) the degree of lung function abnormalities and exercise limitation due to added resistances (as a model for UAO); and 2) to relate the lung function abnormalities, $\mathrm{MBCm}, \mathrm{MBC}, V^{\prime} \mathrm{Emax}$ and exercise capacity to each other in order to establish the clinical relevance of each of these changes.

\section{Subjects and method}

\section{Subjects}

Nine healthy, nonsmoking, male volunteers (age $36 \pm 9$ yrs, height $176 \pm 4 \mathrm{~cm}$, weight $75 \pm 9 \mathrm{~kg}$ ) without history or clinical signs of COPD, asthma or other lung disorders were investigated. All gave informed consent prior to the investigations and the study was approved by the Ethics Committee.

\section{Methods}

Vital capacity (VC), FEV1, forced inspiratory volume in one second (FIV1), maximal expiratory and inspiratory flow-volume-curves (MEFV- and MIFV-curves) were recorded at the mouth with a Lilly-type pneumotachograph and integrator (Medical Graphics, St. Paul, MN, USA). Airway resistance (Raw) was measured at functional residual capacity (FRC) in a constant-volume plethysmograph (Medical Graphics) as the chord slope between inspiratory and expiratory flow at $0.5 \mathrm{~L} \cdot \mathrm{s}^{-1}$; specific airway res-istance (sGaw) was calculated as $1 / R$ aw $\times$ FRC. All lung function values were also expressed in $\%$ control or $\%$ predicted of the reference values of the European Community for Steel and Coal (ECSC) [20]. MBC was cal-culated as MBCc $=$ $37.5 \times \mathrm{FEV} 1[21,22]$ and was also measured as $\mathrm{MBCm}$ by performing a MBC-manoeuvre during $15 \mathrm{~s}$. Pulmonary function testing was carried out according to the ECSCand American Thoracic Society (ATS)-recommendations $[20,23]$ in control conditions and with two added resistances $(\mathrm{R} 1=7.8 \mathrm{~mm}$ cross-sectional diameter, and $\mathrm{R} 2=5.7$ $\mathrm{mm})$. The resistances were made of 3-cm-long cylinders of metal and hard poly vinyl chloride (PVC) inserted in each other [24]. They were placed be-tween the mouth and the pneumotachograph and had a dead space of $<2$ $\mathrm{mL}$.

Exercise testing was done on a cycle-ergometer (Part'nair 5400, version 5.0, Medisoft, Belgium and Ergometrics 900 computer, Ergoline, Germany) by 2-min increments of 30 Watt (pedalling at 60 cycles. $\mathrm{min}^{-1}$ ), until exhaustion or a symptom-limited maximum occurred. All exercise tests were performed under 12-lead-electrocardiographic monitoring from which heart rate (HR) was obtained. The subject breathed through a mouthpiece in a three-way valve type, adapted Otis-McKerrow (dead space $100 \mathrm{~mL}$ ). Ex-pired gas passed through a mixing chamber at the outlet at which $V^{\prime}$ E was obtained from a Lilly type pneumotachograph with integrator (Medisoft); and mixed expired $\mathrm{O}_{2}$ and $\mathrm{CO}_{2}$ levels with a paramagnetic oxygen analyser and an infra-red carbon dioxide analyser (Medisoft). From these, oxygen uptake $\left(V^{\prime} \mathrm{O}_{2}\right), \mathrm{CO}_{2}$ elimination $\left(V^{\prime} \mathrm{CO}_{2}\right)$, respiratory quotient $\left(\mathrm{RQ}=V^{\prime} \mathrm{CO}_{2} / V^{\prime} \mathrm{O}_{2}\right), V^{\prime} \mathrm{O}_{2} / \mathrm{HR}, V^{\prime} \mathrm{E} / V^{\prime} \mathrm{O}_{2}$ and $V^{\prime} \mathrm{E} /$ $V^{\prime} \mathrm{CO}_{2}$ were calculated. Before each exercise test, volume recordings were calibrated with a $3 \mathrm{~L}$ syringe along with gas analyses for precise gas mixtures. Arterial or transcutaneous blood gases were not measured. Tests were done on 3 separate days: first the control exercise (R0) was performed, and thereafter the exercises with $\mathrm{R} 1$ and $\mathrm{R} 2$ in random order. The resistances $(<2 \mathrm{~mL}$ dead space) were placed between the mouth and the three-way valve. Results were expressed in absolute values and in per cent of control [25].

\section{Statistical analysis}

All data are presented as means \pm 1 standard deviation (SD). Analysis of variance was applied and when this was statistically significant a Duncan test was added to determine between which resistances differences were significant. The level of significance was set at $\mathrm{p}<0.05$.

\section{Results}

Table 1 shows the lung function values for the nine subjects in control condition (R0) and with the two added resistances ( $\mathrm{R} 1$ and $\mathrm{R} 2)$ in absolute values and in \% control. While FEV1 hardly decreases, not even with R2, mark-ed changes occur in FIV1, PEF, PIF, Raw and sGaw, even with $\mathrm{R} 1$. The classical ratios for UAO are clearly fulfilled with both resistances: PEF/maximal expiratory flow at $50 \% \mathrm{VC}$ (MEF50) (\% pred/\% pred) becomes markedly <2.1, FEV1/ PEF $\left(\mathrm{mL} \cdot \mathrm{L}^{-1} \cdot \mathrm{min}\right)$ becomes $>8-10$, and MEF50/airway conductance $(G \mathrm{aw})(\mathrm{kPa})$ is $>0.7$ [5, 26-29]. MEF50/ MIF50 is clearly $>1$ which is in agreement with a previous analysis by us in fixed UAO [24]. In addition, the $\mathrm{MBCm}$ is markedly reduced with both resistances and becomes only $\sim 50 \%$ of the MBCc. The rather large SD for PEF, Raw and ${ }_{\mathrm{s}} G$ aw with $\mathrm{R} 2$ are most likely due to the alinear pressureflow characteristics of R2 (see characteristics in [24]).

Table 2 shows the results of the maximal cycloergometric test. Standard deviations for the different values with $\mathrm{R} 1$ and $\mathrm{R} 2$ are small, indicating that the different subjects adapted similarly to these resistances. All values are normal in control condition (e.g. $W^{\prime} \max =110 \pm 28 \%$ pred) [25]. With R1, there is already a tendency for decreases in $W^{\prime} \max , V^{\prime} \mathrm{O}_{2} \max$ and maximal heart rate (HRmax), but these are not significant; yet the decreases in maximal $V^{\prime} \mathrm{CO}_{2}$ and especially in $V^{\prime}$ 'Emax are more pronounced, and are significant. With R2, all values are markedly and significantly reduced: HRmax is clearly not maximal and RQ is below 1 , indicating that no cardioperipheral limit is reached and that the decreased exercise capacity has to be attributed to a ventilatory limitation, despite the fact that $V^{\prime} E \operatorname{Eax}$ is only $62 \pm 17 \% \mathrm{MBCm}$ and only $28 \pm 6 \% \mathrm{MBC}$. 
Table 1. - Lung function data in control situation $(\mathrm{R} 0)$ and with two added resistances ( $\mathrm{R} 1$ and $\mathrm{R} 2)$

\begin{tabular}{|c|c|c|c|c|c|}
\hline & & $\begin{array}{c}\mathrm{R} 0 \\
\text { Control }\end{array}$ & $\begin{array}{c}\mathrm{R} 1 \\
(\varnothing 7.8 \mathrm{~mm})\end{array}$ & $\begin{array}{c}\mathrm{R} 2 \\
(\varnothing 5.7 \mathrm{~mm})\end{array}$ & Duncan \\
\hline \multirow[t]{2}{*}{ FEV1 } & $\mathrm{L}$ & $4.6 \pm 0.6$ & $4.5 \pm 0.6$ & $3.4 \pm 0.8$ & $\mathrm{R} 0 \mathrm{R} 1 \mathrm{R} 2$ \\
\hline & $\%$ control & 100 & $98 \pm 10$ & $74 \pm 16$ & $\mathrm{R}_{0} \mathrm{R} 1-\mathrm{R} 2$ \\
\hline \multirow[t]{2}{*}{ FIV } & $\mathrm{L}$ & $5.0 \pm 1.0$ & $3.6 \pm 1.2$ & $2.3 \pm 1.4$ & R0-R1-R2-R0 \\
\hline & $\%$ control & 100 & $72 \pm 23$ & $46 \pm 26$ & R0-R1-R2-Ro \\
\hline \multirow[t]{2}{*}{ PEF } & $\mathrm{L} \cdot \mathrm{S}^{-1}$ & $11.0 \pm 0.8$ & $7.2 \pm 0.8$ & $5.0 \pm 2.8$ & R0-R1-R2-R0 \\
\hline & $\%$ control & 100 & $66 \pm 10$ & $45 \pm 26$ & R0-R1-R2-R0 \\
\hline \multirow[t]{2}{*}{ PIF } & $\mathrm{L} \cdot \mathrm{S}^{-1}$ & $7.9 \pm 2.1$ & $4.3 \pm 1.0$ & $3.2 \pm 1.6$ & $\mathrm{R}_{0}-\mathrm{R}_{1} \mathrm{R} 2$ \\
\hline & $\%$ control & 100 & $54 \pm 13$ & $41 \pm 20$ & $\mathrm{R}_{0}-\mathrm{R}_{1} \mathrm{R}_{2}$ \\
\hline \multirow[t]{2}{*}{ Raw } & $\mathrm{kPa} \cdot \mathrm{L}^{-1} \cdot \mathrm{S}^{-1}$ & $0.13 \pm 0.04$ & $0.35 \pm 0.07$ & $0.78 \pm 0.36$ & $\mathrm{R}_{0}-\mathrm{R}_{1}-\mathrm{R}_{2}-\mathrm{R}_{0}$ \\
\hline & $\%$ control & 100 & $275 \pm 50$ & $605 \pm 280$ & R0-R1-R2-R0 \\
\hline \multirow[t]{2}{*}{ s $G$ aw } & $\mathrm{kPa}^{-1} \cdot \mathrm{s}^{-1}$ & $2.16 \pm 0.65$ & $0.69 \pm 0.13$ & $0.54 \pm 0.75$ & R0-R1R2 \\
\hline & $\%$ control & 100 & $31 \pm 7$ & $25 \pm 35$ & R0-R1R2 \\
\hline \multirow[t]{2}{*}{$\mathrm{MBCm}$} & $\mathrm{L} \cdot \min ^{-1}$ & $153 \pm 23$ & $94 \pm 25$ & $63 \pm 26$ & R0-R1-R2-R0 \\
\hline & $\%$ control & 100 & $61 \pm 13$ & $41 \pm 17$ & R0-R1-R2-R0 \\
\hline $\mathrm{MBCm} / \mathrm{FEV} 1$ & $\mathrm{~L} \cdot \min ^{-1}$ & $34.1 \pm 6.5$ & $21.3 \pm 7.1$ & $18.2 \pm 6.5$ & $\mathrm{R}_{0}-\mathrm{R}_{1} \mathrm{R} 2$ \\
\hline $\mathrm{MBC} / \mathrm{MBC}$ & $\times 100$ & $91 \pm 17$ & $57 \pm 19$ & $48 \pm 17$ & $\mathrm{R}_{0}-\mathrm{R}_{1} \mathrm{R}_{2}$ \\
\hline PEF/MEF50 & $\%$ pred $/ \%$ pred & $2.1 \pm 0.4$ & $1.4 \pm 0.3$ & $1.4 \pm 0.5$ & $\mathrm{R}_{0}-\mathrm{R}_{1} \mathrm{R}_{2}$ \\
\hline $\mathrm{FEV}_{1} / \mathrm{PEF}$ & $\mathrm{mL} \cdot \mathrm{L}^{-1} \cdot \min$ & $6.9 \pm 0.9$ & $10.5 \pm 1.8$ & $12.9 \pm 3.3$ & R0-R1-R2-R0 \\
\hline MEF50/Gaw & $\mathrm{kPa}$ & $0.6 \pm 0.2$ & $1.9 \pm 0.6$ & $2.4 \pm 0.9$ & R0-R1-R2-R0 \\
\hline MEF50/MIF50 & $\mathrm{L} \cdot \mathrm{S}^{-1} / \mathrm{L} \cdot \mathrm{S}^{-1}$ & $0.8 \pm 0.3$ & $1.4 \pm 0.5$ & $1.4 \pm 0.3$ & R0-R1R2 \\
\hline
\end{tabular}

Data are mean \pm SD; FEV1/FIV1: forced expiratory/inspiratory volume in one second; PEF/PIF: peak expiratory/inspiratory flow; MEF50/MIF50: maximal expiratory/inspiratory flow at 50\% vital capacity; Raw: airway resistance; sGaw: specific airway conductance; $G$ aw: airway conductance; $\mathrm{MBCm} / \mathrm{MBC}$ : measured/calculated maximal breathing capacity; groups separated by a dash in Duncan test differ significantly $(\mathrm{p}<0.05)$ e.g. $\mathrm{R} 0-\mathrm{R}_{1} \mathrm{R}_{2}$ means $\mathrm{R} 0$ is different from $\mathrm{R} 1$ and $\mathrm{R} 2$, but that $\mathrm{R} 1$ and $\mathrm{R} 2$ are not different from each other.

Table 2. - Maximal breathing capacity and cardioperipheral and respiratory indices during maximal exercise in control situation $\mathrm{R}_{0}$ and with two added resistances ( $\mathrm{R}_{1}$ and $\left.\mathrm{R} 2\right)$

\begin{tabular}{|c|c|c|c|c|c|}
\hline & & $\begin{array}{c}\text { R0 } \\
\text { (control) }\end{array}$ & $\begin{array}{c}\mathrm{R} 1 \\
(\varnothing 7.8 \mathrm{~mm})\end{array}$ & $\begin{array}{c}\mathrm{R}_{2} \\
(\varnothing 5.7 \mathrm{~mm})\end{array}$ & Duncan \\
\hline Exercise duration & $\min$ & $16.3 \pm 3.3$ & $15.1 \pm 3.3$ & $10.4 \pm 1.8$ & R0R1-R2 \\
\hline \multirow[t]{2}{*}{$W^{\prime} \max$} & watt & $248 \pm 47$ & $223 \pm 44$ & $153 \pm 26$ & RoR1-R2 \\
\hline & $\%$ control & 100 & $91 \pm 18$ & $62 \pm 11$ & RoR1-R2 \\
\hline \multirow{2}{*}{$V^{\prime} \mathrm{O}_{2} \max$} & $\mathrm{L} \cdot \mathrm{min}^{-1}$ & $3.5 \pm 0.8$ & $3.1 \pm 0.8$ & $1.9 \pm 0.4$ & R0R1-R2 \\
\hline & $\%$ control & 100 & $88 \pm 23$ & $54 \pm 11$ & RoR1-R2 \\
\hline \multirow[t]{2}{*}{$V^{\prime} \mathrm{CO}_{2} \max$} & $\mathrm{L} \cdot \mathrm{min}^{-1}$ & $4.3 \pm 0.9$ & $3.5 \pm 1.0$ & $1.8 \pm 0.5$ & R0-R1-R2-R0 \\
\hline & $\%$ control & 100 & $81 \pm 23$ & $42 \pm 12$ & R0-R1-R2-R0 \\
\hline \multirow[t]{2}{*}{ HR } & $\min ^{-1}$ & $179 \pm 12$ & $170 \pm 15$ & $143 \pm 23$ & RoR1-R2 \\
\hline & $\%$ control & 100 & $94 \pm 9$ & $76 \pm 12$ & $\mathrm{R} 0 \mathrm{R} 1-\mathrm{R} 2$ \\
\hline RQ & & $1.3 \pm 0.1$ & $1.1 \pm 0.1$ & $0.9 \pm 0.1$ & R0-R1-R2 \\
\hline \multirow[t]{2}{*}{$V^{\prime}$ Emax } & $L \cdot \min ^{-1}$ & $102 \pm 23$ & $66 \pm 18$ & $34 \pm 7$ & R0-R1-R2-R0 \\
\hline & $\%$ control & 100 & $66 \pm 15$ & $34 \pm 6$ & R0-R1-R2-R0 \\
\hline$f$ Rmax & $\min ^{-1}$ & $33 \pm 8$ & $25 \pm 8$ & $18 \pm 5$ & R0-R1-R2-R0 \\
\hline$V^{\prime}$ Emax/MBCc & $\times 100$ & $60 \pm 12$ & $41 \pm 15$ & $28 \pm 6$ & R0-R1-R2-R0 \\
\hline$V^{\prime} \operatorname{Emax} / \mathrm{MBCm}$ & $\times 100$ & $66 \pm 12$ & $70 \pm 26$ & $62 \pm 17$ & R0R1R2 \\
\hline
\end{tabular}

Data are mean $\pm \mathrm{SD} ; W^{\prime} \max$ : maximum exercise capacity; $\mathrm{V}^{\prime} \mathrm{O}_{2} \max$ : maximal oxygen uptake; $\mathrm{V}^{\prime} \mathrm{CO}_{2} \max$ : $\max -$ imal carbon dioxide production; HR: heart rate; RQ: respiratory quotient; $V^{\prime}$ Emax: maximal exercise ventilation; $f R \max$ : maximal respiratory frequency; $M B C c / M B C m$ : measured/calculated maximal breathing capacity; R1 and R2: added resistances; groups separated by a dash in Duncan test differ significantly $(\mathrm{p}<0.05)$.

Figures 1-4 show the changes in $V^{\prime} \mathrm{E}, \mathrm{HR}, V^{\prime} \mathrm{O}_{2}$ and $V^{\prime} \mathrm{E} /$ $V^{\prime} \mathrm{CO}_{2}$ at the different levels of exercise. Figure 1 demonstrates that $V^{\prime} \mathrm{E}$ is lower with $\mathrm{R} 1$ than with $\mathrm{R} 0$ and that the difference is significant at exercise levels of Š 140 W. With $\mathrm{R}_{2} V^{\prime} \mathrm{E}$ is significantly lower than with $\mathrm{R} 0$ and $\mathrm{R} 1$ already at exercise levels of S $80 \mathrm{~W}$; this decrease is mainly due to a decrease in breathing frequency (not shown). In addition, the increase in $V^{\prime} \mathrm{E}$ with increasing exercise levels tends to level off with $\mathrm{R} 2$ at $170 \mathrm{~W}$ (suggesting a ventilatory limitation) while it increases curvilinearly at this level with $\mathrm{R} 0$ and R1. Similarly $V^{\prime} \mathrm{CO}_{2}$ is significantly lower with $\mathrm{R} 2$ than with $\mathrm{R} 0$ and $\mathrm{R} 1$ from 80 Watt on (not shown) and $V^{\prime} \mathrm{CO}_{2}$ levels off with $\mathrm{R} 2$ at $170 \mathrm{~W}$ (indicating hypoven-tilation) while it increases curvilinearly at this level with $\mathrm{R} 0$ and $\mathrm{R} 1$ (not shown). Figure 2 shows that the $V^{\prime} \mathrm{E} / V^{\prime} \mathrm{CO}_{2}$ ratio also changes between $\mathrm{R} 0$ and $\mathrm{R} 1$ at high exercise levels of $\breve{S} 200 \mathrm{~W}$. Figure 3 indicates that $V^{\prime} \mathrm{O}_{2}$ is very similar with $\mathrm{R} 0, \mathrm{R} 1$ and $\mathrm{R} 2$ at the different exercise levels, except for the highest exercise level attained with $\mathrm{R} 2$. The $V^{\prime} \mathrm{CO}_{2} / V^{\prime} \mathrm{O}_{2}$ ratio (i.e. RQ) is significantly lower with R2 at several moderately high exercise levels: at 170 $\mathrm{W}$, the highest level with $\mathrm{R} 2$, it is only $0.95 \pm 0.09$, while 


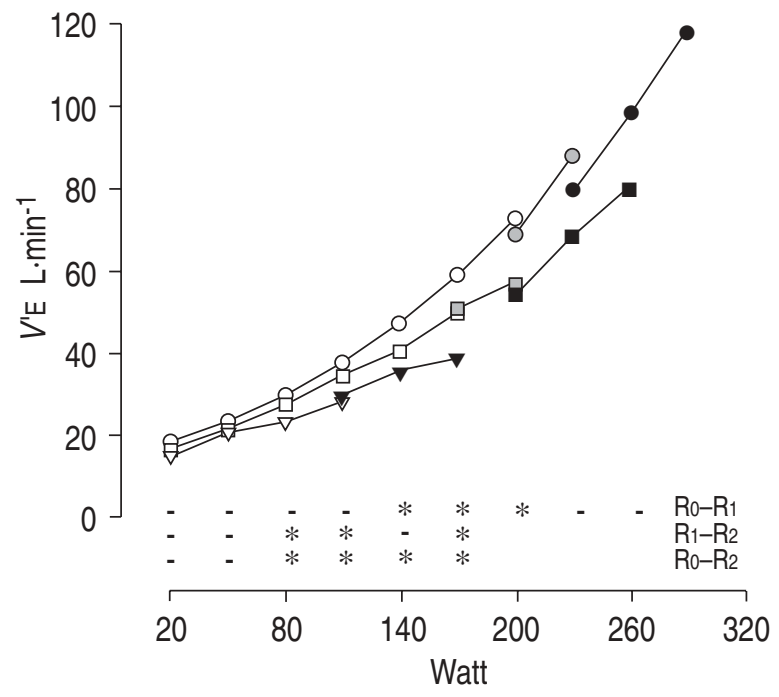

Fig. 1. - Relationship between minute ventilation ( $\left.V^{\prime} \mathrm{E}\right)$ and exercise level (Watt) in control condition ( $\mathrm{R} 0$, circles), with an added resistance of $7.8 \mathrm{~mm}$ diameter ( $\mathrm{R} 1$, squares) and of $5.7 \mathrm{~mm}$ (R2, triangles). Shading of symbols indicate number of subjects for each condition as follows: $\bigcirc=9 ; \bigcirc=6 ; \bullet=3 ; \square=9 ; \square=8 ; \square=3 ; \widehat{c}=9 ;$ and $\boldsymbol{\nabla}=5$. Significance $(\mathrm{p}<0.005)$ of differences $\mathrm{R} 0, \mathrm{R} 1$ and $\mathrm{R} 2$ are shown by the asterisks.

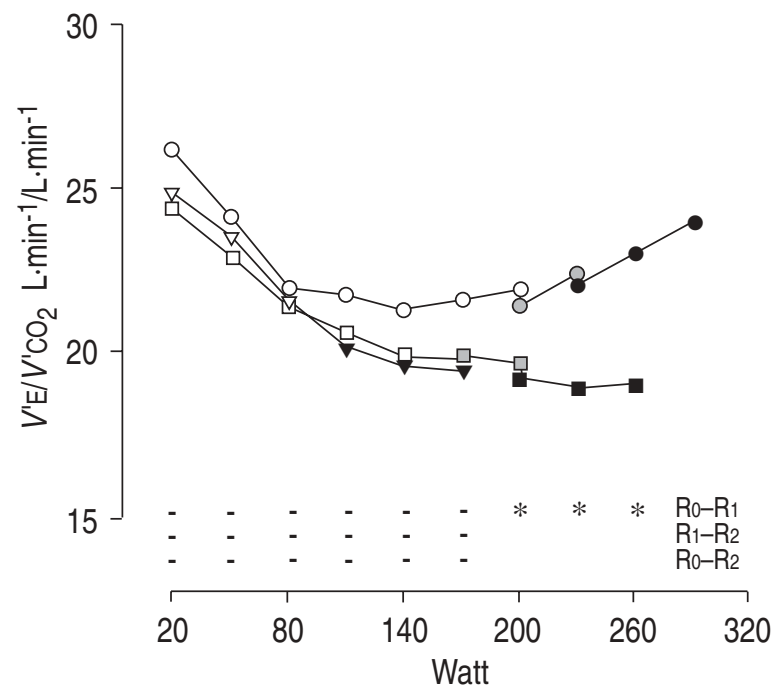

Fig. 2. - Relationship between (exercise ventilation $\left(V^{\prime} \mathrm{E}\right) / \mathrm{carbon}$ dioxide production $\left(V^{\prime} \mathrm{CO}_{2}\right)$ ) and exercise level in control condition $(\mathrm{R} 0)$ and with added resistances R1 and R2. For explanation see legend to figure 1.

it is already $1.03 \pm 0.07$ with $\mathrm{R} 1$, and $1.09 \pm 0.08$ with $\mathrm{R} 0$ (not significant). Figure 4 shows that HR at each exercise level is equal with the different resistances; as expected, it is low-er for the best trained subjects who achieve the highest exercise levels. Also the $V^{\prime} \mathrm{O}_{2} / \mathrm{HR}$ ratio is not significantly different between $\mathrm{R} 0, \mathrm{R} 1$ and $\mathrm{R} 2$ at each exercise level but the maximal $V^{\prime} \mathrm{O}_{2} / \mathrm{HR}$ ratio decreases from 19.7 $\pm 4.0 \mathrm{~L}$ with $\mathrm{R} 0$, to $18.8 \pm 5.4 \mathrm{~L}$ with $\mathrm{R} 1$ and to $14.0 \pm 3.5$ $\mathrm{L}$ with $\mathrm{R} 2$ ( $\mathrm{p}<0.05$ for $\mathrm{R} 2$ versus $\mathrm{R} 0$ and $\mathrm{R} 1)$.

In figure 5, the relationship of different lung function indices (FEV1, FIV1, PEF, PIF, Raw, sGaw and MBC) with $V^{\prime}$ Emax (left panels) and with $W^{\prime} \max$ (right panels) can be approximated. FIV1, in particular, but also PEF and $\mathrm{MBCm}$ show an almost linear relationship with $V^{\prime}$ Emax and $R$ aw,

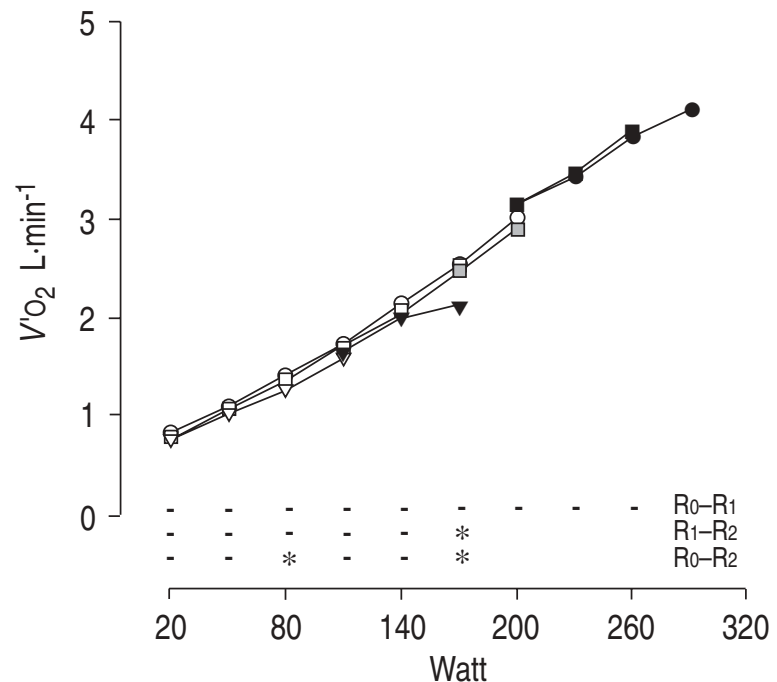

Fig. 3. - Relationship between oxygen uptake $\left(V^{\prime} \mathrm{O}_{2}\right)$ and exercise level in control condition ( $\left.\mathrm{R}_{0}\right)$ and with added resistances $\mathrm{R}_{1}$ and $\mathrm{R}_{2}$. For explanation see legend to figure 1 .

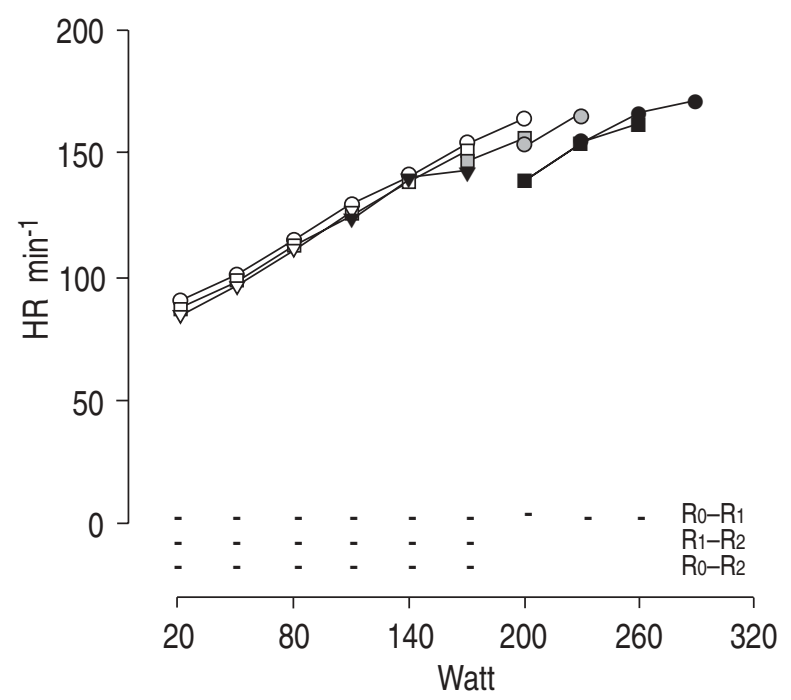

Fig. 4. - Relationship between heart rate (HR) and exercise level in control condition $(\mathrm{R} 0)$ and with added resistances $\mathrm{R} 1$ and $\mathrm{R} 2$. For explanation see legend to figure 1 .

but also $\mathrm{FEV} 1$ or $\mathrm{MBC}$ (which in \% control is identical as FEV1) show an almost linear relationship with $W^{\prime}$ max.

\section{Discussion}

The influence of two added resistances $(\mathrm{R} 1=7.8 \mathrm{~mm}$ and $\mathrm{R} 2=5.7 \mathrm{~mm}$ ) on lung function and on maximal exercise capacity were studied in nine male healthy subjects, as a model for tracheal stenosis. FEV1 was clearly less disturbed than FIV1, PEF, PIF, Raw or sGaw with both resistances which has already been demonstrated [3, 5, 26]. $W^{\prime} \max$ was only clearly reduced with $\mathrm{R} 2$ and was rather linearly related to Raw, FEV1 (or $\mathrm{MBC}$ ). Together, a decrease of $W^{\prime} \max$ to $60 \%$ control corresponds in UAO with a FEV1 of $75 \%$ control, a PEF of $40 \%$ and Raw of $600 \%$. R2 (i.e. a diameter of $<6 \mathrm{~mm}$ ) clearly induced a ventilatory limitation with an impaired $\mathrm{CO}_{2}$ elimination and a RQ $<1$ due to hypoventilation similarly as in other studies [26]. However, $V^{\prime}$ Emax was only $\sim 60 \% \mathrm{MBCm}$ and only 

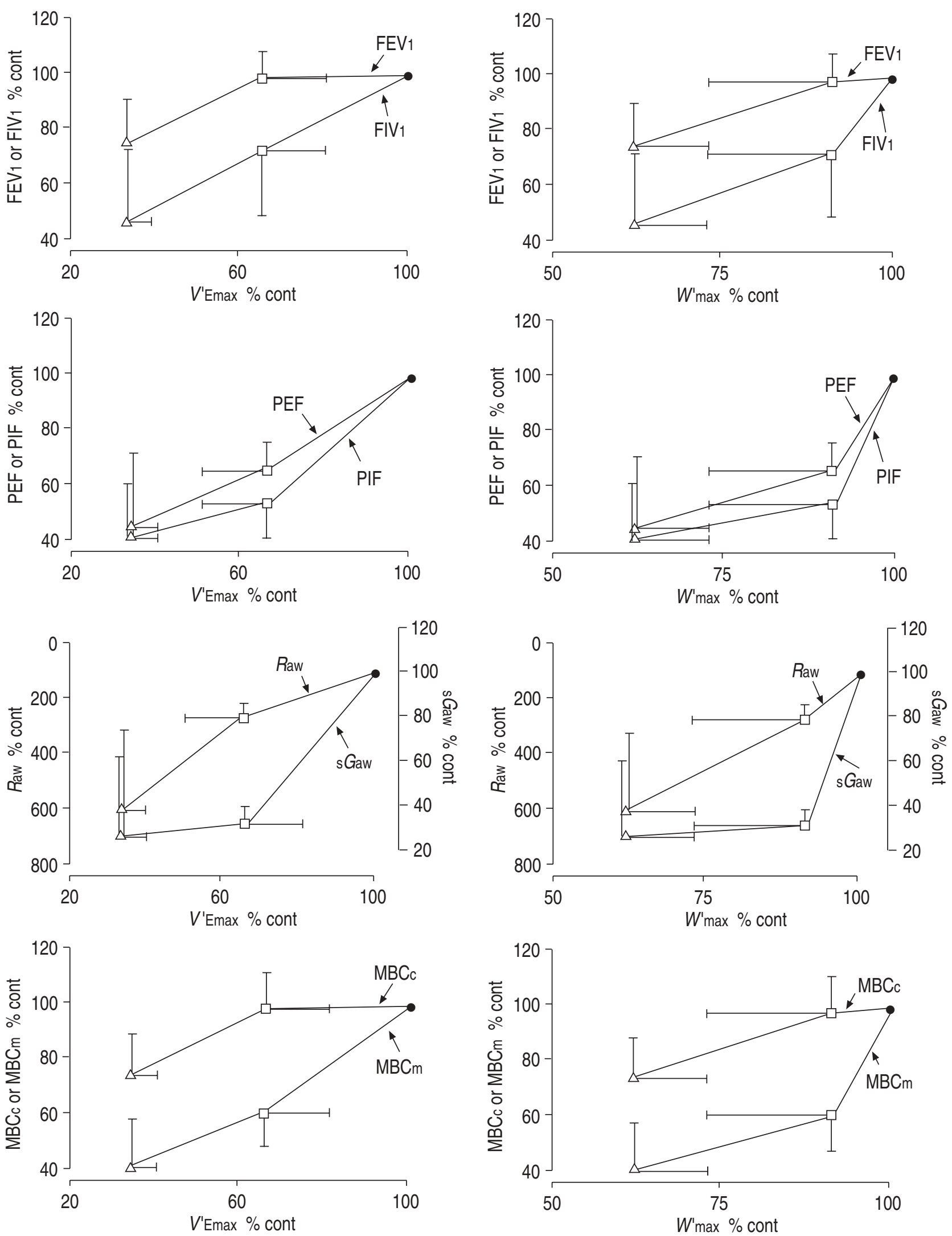

Fig. 5. - Relationship of several lung function indices with maximum exercise ventilation ( $V$ 'Emax) (left panels) and with maximum exercise capacity $\left(W^{\prime} \max \right)$ (right panels) in control condition $(\bullet)$ and with R1 ( $\left.\square\right)$ and R2 (ý). All data are expressed as per cent of the control value (\% cont). FEV1 or FIV1: forced expiratory/inspiratory volume in one second; PEF or PIF: peak expiratory/inspiratory flow; Raw: airway resistance; sGaw: specific airway conductance; $\mathrm{MBC}$ or $\mathrm{MBC}$ : measured/calculated maximal breathing capacity. 
even $\sim 30 \%$ MBCc indicating that MBCc cannot be used as a criterion for ventilatory limitation in UAO. It should be noted that the hypoventilation and reduced $\mathrm{CO}_{2}$ elimination with R2 were already significant at $80 \mathrm{~W}$, indicating that a UAO of $6 \mathrm{~mm}$ impairs lung gas homeostasis during moderate exercise. Furthermore, R1 (diameter of $<8 \mathrm{~mm}$ ) had only minor effects on $W^{\prime} \max (\sim 90 \%$ control), but re-duced $V^{\prime} \mathrm{E}$ and $V^{\prime} \mathrm{E} / V^{\prime} \mathrm{CO}_{2}$ at the higher exercise levels, suggesting an impairment in lung gas homeostasis during more strenuous exercise. This confirms the data of the literature which point towards the occurrence of hypoxia and hypercapnia during strenuous exercise in UAO [8, 13, 27-29].

It is well known that the relative changes in different lung function tests in UAO are quite different from those in COPD or in lung fibrosis and therefore, several ratios may have a diagnostic value for UAO e.g. PEF/MEF50, FEV 1/PEF and FEV1/Raw [5, 30-34]. It is, however, much less clear which lung function test provides the most relevant information in UAO to estimate the severity of the obstruction and the degree of exercise limitation in this condition. In agreement with data of the literature we confirmed that in particular, sGaw and $V^{\prime}$ Emax were most affected (see tables 1 and 2) and thus probably were the most sensitive indices in this type of fixed UAO, followed by $\mathrm{MBCm}$, PEF, PIF and FIV1 while FEV1 was an insensitive index which tends to underestimate the degree of UAO [8, 13, 18, 26]. MBC has been considered to be a sensitive index of UAO [3,8-13], and it could also be hypothesized that MBC may be a good indicator of exercise limitation in UAO, because UAO will cause a ventilatory type of exercise limitation. However, the classical relationship between FEV1, $V^{\prime}$ Emax and MBC (MBC 37.5 $\times$ FEV $1 ; V^{\prime}$ Emax $\breve{S} 70 \%$ MBC) does not hold in UAO [3, $10,11,15]$. MBC is often applied in COPD or lung fibrosis to estimate whether a reduced exercise capacity is due to a ventilatory limitation (i.e. $V^{\prime}$ Emax approaches $\mathrm{MBC}$ ). It is obvious that this calculation of MBC cannot be applied to UAO since, even in a ventilatory limitation, $V^{\prime}$ Emax will not approach MBCc: in our study $V^{\prime}$ Emax is only $\sim 30 \%$ $\mathrm{MBC}_{\mathrm{c}}$ with $\mathrm{R} 2$. In addition, even $\mathrm{MBCm}$ is only $\sim 50 \%$ $\mathrm{MBC}_{\mathrm{c}}$ with R2. The reason is, of course, that MBCc, similarly to FEV1, only reflects expiratory limitation, and while in COPD the limitation is, indeed, only expiratory, this is not the case in UAO. The actual ratio between $\mathrm{MBCm}$ and FEV1 in our healthy subjects was, as expected, 235 in control condition, but it decreased to $\sim 20$ with $\mathrm{R} 1$ and $\mathrm{R} 2$ (table 1). More important is that despite the clear ventilatory limitation during maximal exercise with $\mathrm{R} 2, V^{\prime}$ Emax did not approach $\mathrm{MBCm}$ but remained at $60-70 \%$ of it, similar to the control situation in healthy subjects $[35,36]$. This confirms the data of DEMEDTS and ANTHONISEN [13] that $V$ 'Emax is $~ 70 \%$ of the $15 \mathrm{~s} \mathrm{MBC}$ independent of the level of external resistance. The reason why $V$ 'Emax does not come closer to $\mathrm{MBCm}$ in UAO is obvious: if maximum voluntary ventilation (MVV) is sustained for several minutes it will progressively decrease due to respiratory muscle fatigue. It has, indeed, been shown even in healthy subjects that after 4 min MVV will only be $\sim 70 \%$ MBC (with interindividual ranges from 40-90\%) and this has been attributed to respiratory muscle fatigue with time [36-38]. It is less likely that the rather low $V^{\prime} \mathrm{Emax} / \mathrm{MBCm}$ is due to differences in breathing pattern between the $\mathrm{MBCm}$ and maximal exercise. Indeed, in contrast with COPD, where there is a tendency for faster breathing at a high lung level during the $\mathrm{MBCm}$, this is not the case in UAO due to the plateau-shaped maximal flow-volume curve. In-deed, table 2 shows that with increasing resistance, breathing frequency decreases markedly at $V^{\prime} \max$, and it should also be noted that at the different submaximal exercise levels, breathing frequency was lower with the higher resistances.

Another aim of the study was to investigate which lung function test was best related to $V^{\prime}$ Emax and to $W^{\prime} \max$, and thus allow the most accurate prediction of exercise limitation in UAO. From the three points on figure 2 it can be estimated that especially FIV1 and also PEF and $\mathrm{MBCm}$ are relatively linearly related with $V^{\prime} E \max$, it can also be roughly estimated that (each) $10 \%$ decrease in $V^{\prime}$ Emax was related to a $8.5 \%$ decrease in PEF or FIV1 and a 9\% decrease in $\mathrm{MBCm}$. However, $V^{\prime} \mathrm{Emax}$ is not linearly related with $W^{\prime}$ max. It should be noted that besides $R$ aw, FEV1, (or $\mathrm{MBCc}$ ) but not $\mathrm{MBCm}$ presents a linear relationship with $W^{\prime}$ max: a rough estimation shows that (each) $10 \%$ decrease in $W^{\prime}$ max was related to a $7 \%$ decrease in FEV1 (or $\mathrm{MBC}$ ) and a $150 \%$ increase in Raw. It is not clear to what extent these relationships, which we deducted from added resistances (as a model for UAO), can be applied to real UAO. In real UAO it is difficult to obtain reliable in vivo estimations of the degree of anatomic stenosis. Indeed, there is not a good correlation between the degree of a tracheal stenosis on radiograph and computed tomography (CT)-scan [19] or magnetic resonance imaging (unpublished observation). There is also no good correlation between the radiological estimates of the stenosis and the lung function abnormalities [19]. Of course, added resistances enable one to relate accurately the degree of the obstruction (i.e. diameter of resistance) to functional abnormalities [3, 35]; graphs have also been constructed relating several lung function tests (e.g. FEV1, PEF, etc.) to the diameter of this added obstruction [3]. Plotting lung function data of patients with real UAO on these graphs shows good agreement with the effects of added resistances $[39,40]$. This suggests that in real UAO the effective degree of obstruction can be derived from the lung function co-ordinates on these graphs. However, more elaborate studies are warranted to confirm these preliminary data.

A final important consideration is that the relationship between the lung function abnormalities at rest and the exercise limitation appears to be markedly different between UAO and COPD, and this is probably largely attributable to the fact that airflow limitation is only expiratory in COPD but inspiratory as well as expiratory in UAO. An UAO of $\sim 8 \mathrm{~mm}$ allows a $W^{\prime}$ max of $90 \%$ control, while FEV 1 is still $\sim 100 \%$ control, but PEF only $\sim 65 \%$ and Raw $\sim 250 \%$. In COPD with a similar $W^{\prime} \max$ of $90 \%$ pred, FEV 1 is clearly reduced to $\sim 70 \%$ pred, with a PEF of $75 \%$ pred and a Raw of only $\sim 150 \%$ [2]. Furthermore, an UAO of $\sim 6$ $\mathrm{mm}$, causes a reduction in $W^{\prime} \max$ to about $60 \%$ control, while FEV1 is still $75 \%$, but PEF is reduced to $40 \%$ and $R$ aw increased to $600 \%$. In COPD with a similar $W^{\prime}$ max of $60 \%$ pred, FEV 1 is markedly reduced to $55 \%$ pred with a PEF of $60 \%$ and Raw of only $200 \%$ [2]. Thus, as far as $W$ 'max is concerned, decreases in PEF to $60-65 \%$ and increases in Raw to 200-250\% are almost irrelevant in UAO but mod-erately detrimental in COPD, and vice versa for a reduction in FEV1 to 70-75\%. Published tables with esti- 
mates of physical impairment based on lung function abnormalities at rest in COPD, pneumoconiosis and possibly interstitial lung disease $[1,2]$ are therefore not applicable to UAO [40].

In conclusion, this study provides information on the relationship between the degree of airway obstruction, lung function abnormalities and the corresponding exercise capacity in artificial upper airway obstruction. To what extent this model of added resistances can also be applied to clinical upper airway obstruction requires further investigation.

\section{References}

1. American Thoracic Society. Evaluation of impairment/ disability secondary to respiratory disorders. Am Rev Respir Dis 1986; 133: 1205-1209.

2. Werkgroep van de Belgische Vereniging voor Pneumologie. Voorstel tot herziening van de "Officiële Belgische Schaal ter bepaling van de graad van invaliditeit". Deel IV: Ademhalingsstelsel 1990.

3. Miller RD, Hyatt RE. Obstructing lesions of the larynx and trachea: clinical and physiological characteristics. Mayo Clin Proc 1969; 44: 145-161.

4. Miller RD, Hyatt RE. Evaluation of obstructing lesions of the trachea and larynx by flow-volume loops. Am Rev Respir Dis 1973; 108: 475-481.

5. Melissant CF, van Noord JA, van de Woestijne KP, Demedts M. Comparison of dynamic lung function indices during forced and quiet breathing in upper airway obstruction, asthma and emphysema. Chest 1990; 98: 7783.

6. Gaensler EA, Wright GW. Evaluation of respiratory impairment. Arch Environ Health 1966; 2: 146-189.

7. Zamel N, Altose MD, Speiz WA. Statement on spirometry: a report of the section on respiratory pathophysiology. Chest 1983; 83: 547-550.

8. Al-Bazzaz F, Grillo H, Kazemi H. Response to exercise in upper airway obstruction. Am Rev Respir Dis 1975; 111: 631-640.

9. Sackner MA. Physiological features of upper airway obstruction. Chest 1972; 62: 414-417.

10. Shim C, Corro P, Park SS, Williams MH. Pulmonary function studies in patients with upper airway obstruction. Am Rev Respir Dis 1972; 106: 233-238.

11. Owens GR, Murphy DMF. Spirometric diagnosis of upper airway obstruction. Arch Intern Med 1983; 143: 13311334.

12. Wittenborg MH, Gyepes MT, Crocker D. Tracheal dynamics in infants with respiratory distress, stridor and collapsing trachea. Radiology 1967; 88: 653-662.

13. Demedts M, Anthonisen NR. Effects of increased external airway resistance during steady-state exercise. $J$ Appl Physiol 1973; 35: 361-366.

14. Spivey CG, Walsh RE, Perez-Guerra F, Harleroad LE. Central airway obstruction: report of seven cases. JAMA 1973; 226: 1186-1189.

15. Grimby G, Söderholm B. Spirometric studies in normal subjects: static lung volumes and maximum voluntary ventilation in adults with a note on physical fitness. Acta Med Scand 1963; 173: 199-206.

16. Engström H, Grimby G, Söderholm B. Dynamic spirometry in patients with tracheal stenosis. Acta Med Scand 1964; 176: 329-334.

17. Dillard TA, Hnatiuk OW, McCumber TR. Maximum voluntary ventilation: spirometric determinants in chronic obstructive pulmonary disease patients and normal subjects. Am Rev Respir Dis 1993; 147: 870-875.
18. Lindstedt SL, Thomas RG, Leith DE. Does peak inspiratory flow contribute to setting $\mathrm{V}^{\prime} \mathrm{O}_{2} \max$ ? Respir Physiol 1994; 95: 109-118.

19. Melissant CF, Smith SJ, Perlberger R, et al. Lung function, CT-scan and X-ray in upper airway obstruction due to thyroid goiter. Eur Respir J 1994; 7: 1782-1787.

20. Quanjer PH (ed). Standardized lung function testing: Report of working party on "Standardization of lung function tests". Bull Eur Physiopathol Respir 1983; Suppl. 19; $1-95$.

21. Cara M. Synergies et asynergies ventilatoires: la dynamique ventilatoire. Poumon 1953; 9: 406-411.

22. Gandevia B, Hugh-Jones P. Terminology for measurements of ventilatory capacity. Thorax 1957; 12: 290-293.

23. American Thoracic Society. Standardization of spirometry 1987-update. Am Rev Respir Dis 1987; 136: 12851298.

24. Melissant CF, Lammers J-WJ, Demedts M. Rigid external resistances cause effort dependent maximal expiratory and inspiratory flows. Am J Respir Crit Care Med 1995; 152: 1709-1712.

25. Jones LJ, Makrides L, Hitchcock C, Chyphar T, McCartney N. Normal standards for an incremental progressive cycle ergometer test. Am Rev Respir Dis 1985; 131: 700708.

26. Wassermann K, Gitt A, Weyde J, Eckel HE. Lung function changes and exercise-induced ventilatory responses to external resistive loads in normal subjects. Respiration 1995; 62: 177-184.

27. Ceretelli P, Sikand RS, Farhi LE. Effect of increased airway resistance on ventilation and gas exchange during exercise. J Appl Physiol 1969; 27; 597-600.

28. Al-Bazzaz F, Kazemi H. Mechanisms of exercise hypoxemia and dyspnea in tracheal stenosis. Am Rev Respir Dis 1975; 111: 1002-1003.

29. Gee JBL, Burton G, Vassallo C, Gregg J. Effects of external airway obstruction on work capacity and pulmonary gas exchange. Am Rev Respir Dis 1968; 98: 1003-1012.

30. Yernault JC, Englert M, Sergysels R, De Coster A. Upper airway stenosis: a physiological study. Am Rev Respir Dis 1973; 108: 996-1000.

31. Rotman HH, Liss HP, Weg JG. Diagnosis of upper airway obstruction by pulmonary function testing. Chest 1975; 68; 796-799.

32. Empey DW. Assessment of upper airways obstruction. $\mathrm{Br}$ Med J 1972; 3: 503-505.

33. Miller MR, Pincock AC, Oates GD, Wilkinson R, SkeneSmith H. Upper airway obstruction due to thyroid goiter: detection, prevalence and results of surgical management. Q J Med 1990; 274: 177-188.

34. Buyse B, Demedts M. Diagnostic value of Raw/FEV ratio in different diseases. Eur Respir J 1995; 8: Suppl. $19,475 \mathrm{~s}$.

35. Wassermann K, Hansen JE, Sue DY, et al. Principles of exercise testing and interpretation. 1st edn. Philadelphia, Lee \& Febiger, 1987.

36. Weisman IM, Zeballos RJ, eds. Clinical exercise testing. Clin Chest Med 1994; 15: 173-451.

37. Freedman S. Sustained maximum voluntary ventilation. Respir Physiol 1970; 8: 230-244.

38. Babb TG, Rodarte JR. Exercise capacity and breathing mechanics in patients with airflow limitation. Med Sci Sports Exerc 1992; 24: 967-974.

39. Melissant C, Demedts M. Upper airway obstruction: anatomic-functional relationship. Chest 1991; 100: 290-291.

40. Demedts M, Melissant C, Buyse B, Verschakelen J, Feenstra L. Correlation between functional, radiological and anatomical abnormalities in upper airway obstruction (UAO) due to tracheal stenosis. Acta Oto-rhino-laryngol Belg 1995; 49: 331-339. 